\title{
Determination of Mercury in Mainstream Cigarette Smoke by Conventional and Amalgamation Cold Vapor Atomic Absorption Spectrometry*
}

by

\author{
Reta L. McDaniel, Karen M. Torrence, David A. Self and Michael J. Chang
}

Philip Morris U.S.A., Research Development and Engineering Center, U.S.A.

\section{SUMMARY}

A method for differentiation of gas- and particulate-phase mercury in mainstream cigarette smoke was developed using electrostatic precipitation (EP) as the trap for the particulate phase and impingers containing acidic potassium permanganate solution as the trap for the gas-phase portion. The mercury collected from the gas phase was analyzed by conventional cold vapor atomic absorption spectrometry (CVAAS) and the particulate phase was analyzed by gold amalgamation CVAAS. Cigarettes were smoked under two smoking regimes, FTC $(35-\mathrm{mL}$ puff volume, $2 \mathrm{~s}$ puff duration and one puff every $60 \mathrm{~s}$ ) and an alternative $(45-\mathrm{mL}$ puff volume, $2 \mathrm{~s}$ puff duration, one puff every 30 s and $50 \%$ of any ventilation holes blocked) currently recommended by the Massachusetts Department of Health. For the $1 \mathrm{R} 4 \mathrm{~F}$ reference cigarette smoked under the FTC smoking regime, the mercury found in the particulate phase was less than $0.2 \mathrm{ng} / \mathrm{cig}$, compared with $4.9 \mathrm{ng} / \mathrm{cig}$ in the gas phase. By changing smoking parameters, the mercury concentration in mainstream smoke was found to change proportional to the delivery of cigarette smoke condensate (CSC) for the same type of cigarette. However, the mercury level for different types of cigarettes smoked under the same smoking parameters had no linear relationship with CSC delivery. Spiked recovery was $98 \% \pm 8 \%$ for gas-phase mercury and $97 \%$ $\pm 2 \%$ for the particulate phase. These results indicate that the analytical method developed is suitable for the determination of mercury in mainstream smoke. For routine analytical work in a smoking laboratory, only the gas phase needs to be analyzed for determination of mercury in mainstream smoke because the amount of mercury in the particulate phase is negligible. [Beitr. Tabakforsch. Int. 19 (2001) 267-276]

\section{ZUSAMMENFASSUNG}

Es wurde eine Methode zur Differenzierung von Quecksilber in der Gas- und Partikelphase des Hauptstromrauchs von Cigaretten entwickelt, wobei eine elektrostatische Falle als Auffangvorrichtung für die Partikelphase und ein Impinger mit einer sauren Kaliumpermanganatlösung als Auffangvorrichtung für die Gasphase dienten. Das Quecksilber aus der Gasphase wurde mit konventioneller „Cold Vapor"-Atomabsorptionsspektrometrie (CVAAS) und die Partikelphase mit Goldamalgam-CVAAS analysiert. Die Cigaretten wurden unter zwei Abrauchbedingungen geraucht, und zwar unter FTC (Federal Trade Commission) (Zugvolumen $35 \mathrm{~mL}$, Zugdauer 2 Sek., 1 Zug pro Min.) und einer alternativen Abrauchbedingung (Zugvolumen $45 \mathrm{~mL}$, Zugdauer 2 Sek., 1 Zug pro 30 Sek. bei 50\%iger Abdeckung der Ventilationslöcher), die gegenwärtig vom „Massachusetts Department of Health" empfohlen wird. Bei der 1R4F Referenzcigarette, die unter FTC-Bedingungen abgeraucht wurde, betrug der Quecksilberanteil in der Partikelphase weniger als $2 \mathrm{ng} / \mathrm{Cig}$. im Vergleich zu 4,9 ng/Cig. in der Gasphase. Wenn die Abrauchparameter geändert wurden, änderte sich beim selben Cigarettentyp die Quecksilberkonzentration im Hauptstromrauch proportional zur Freisetzung des Cigarettenrauchkondensats (CSC). Es bestand jedoch kein linearer Zusammenhang zwischen der Quecksilbermenge und der Freisetzung von CSC, wenn verschiedene Cigarettentypen unter denselben Abrauchbedingungen geraucht wurden. Die durch Spiken ermittelte Wiederfindung des Quecksilbers aus der Gasphase betrug $98 \% \pm 8 \%$ und $97 \% \pm 2 \%$ aus der Partikelphase. Diese Ergebnisse lassen darauf schließen, dass die entwickelte analytische Methode für die Bestimmung des Quecksilbers im Hauptstromrauch geeignet ist.

*Received: $13^{\text {th }}$ November 2000 - accepted: $2^{\text {nd }}$ February 2001 
Für routinemäßige analytische Arbeiten in einem Rauchlabor muß lediglich die Gasphase bezüglich des Quecksilberanteils im Hauptstromrauch untersucht werden, weil die Quecksilbermenge in der Partikelphase unerheblich ist. [Beitr. Tabakforsch. Int. 19 (2001) 267-276]

\section{RESUME}

Une méthode a été mise au point pour doser séparément la teneur en mercure dans les phases gazeuse et particulaire du courant principal des cigarettes. La phase particulaire est recueillie par précipitation électrostatique (PE) et la phase gazeuse par un piège contenant une solution acide de permanganate de potassium. Le mercure recueilli à partir de la phase gazeuse est analysé par spectrométrie d'absorption atomique à vapeur froide (CVAAS) et la phase particulaire par CVAAS par amalgame avec de l'or. Les cigarettes ont été fumées selon deux régimes de fumage différents, à savoir les conditions de la Federal Trade Commission (FTC) (volume de bouffée $35 \mathrm{~mL}$, durée de bouffée 2 secondes, fréquence de bouffée $1 \mathrm{mi}$ nute) et un régime alternatif (volume de bouffée $45 \mathrm{~mL}$, durée de bouffée 2 secondes, fréquence de bouffée 30 secondes avec $50 \%$ des trous de ventilation étant obstrués), actuellement recommandé par le «Massachusetts Department of Health». Pour la cigarette de référence 1R4F, fumée selon les conditions de la FTC, le niveau de mercure dans la phase particulaire était inférieur à 0,2 $\mathrm{ng} /$ cig. et il était de 4,9 ng/cig. pour la phase gazeuse. Après modification des paramètres de fumage pour le même type de cigarette, la concentration de mercure a varié proportionnellement aux rendements en condensat de fumée de cigarette (CSC). Cependant, quand les différents types de cigarettes ont été fumés selon un même régime de fumage, on n'a pas constaté de relation linéaire entre le niveau de mercure et le rendement en CSC. Le taux de récupération était de $98 \% \pm 8 \%$ pour le mercure présent dans la phase gazeuse et de $97 \% \pm 2 \%$ dans la phase particulaire. Ces résultats indiquent que la méthode mise au point est appropriée à la détermination de la mercure dans le courant principal. Pour les analyses de routine au sein du laboratoire, il suffit d'analyser seulement la phase gazeuse pour connaître la teneur en mercure du courant principal de la fumée, la teneur en mercure de la phase particulaire étant insignifiante. [Beitr. Tabakforsch. Int. 19 (2001) 267-276]

\section{INTRODUCTION}

Although multi-element measurement capability has become an important factor in method development for metal analysis, the determination of mercury is still not routinely included. Mercury distinguishes itself from other metals due to its relatively low boiling point and high volatility, which leads to separation from other metals in the sample matrix and loss of mercury during sample processing. Several methods have been applied to the determination of mercury including graphite furnace atomic absorption spectrometry (GFAAS) (1), inductively coupled plasma atomic emission spectrometry (ICP-AES) (2), and inductively coupled plasma mass spectrometry (ICP-MS) (3-6). However, the most widely used technique for trace mercury analysis has been cold vapor atomic absorption spectrometry (CVAAS) or cold vapor atomic fluorescence spectrometry (CVAFS) $(7,8)$, because of it's sensitivity, selectivity, simplicity, and economics. The ICP-AES technique is not sensitive enough to provide appropriate detection power unless pre-concentration of the mercury is performed prior to analysis. The ICP-MS technique provides the sensitivity to analyze low concentrations of mercury, unfortunately, a $\mathrm{Hg}$ memory effect creates several disadvantages such as longer wash time, poor correlation of the calibration curve, and a continuous decrease in sensitivity. Direct injection nebulization has proven to reduce the memory effect drastically in ICP-MS (3). It has also been found that chemical modification can stabilize mercury and hence reduce the memory effect by adding complexing reagents such as gold, hydrogen iodide, and ethylene diamine tetraacetic acid (EDTA) to the sample matrix $(4,5)$. For even lower detection limit requirements, amalgamation on a gold-platinum gauze is the simplest method for determination of trace mercury by preconcentration without the use of chemicals (6).

Cigarette smoke released from the combustion of tobacco can be classified into mainstream and sidestream smoke. The former refers to the smoke coming out of the butt end of a cigarette during smoking and that coming from the lit end is sidestream smoke. Both mainstream and sidestream smoke have a particulate and a gas phase. The major composition of the gas phase resulting from combustion and thermal degradation of cigarette filler is carbon monoxide, carbon dioxide and water, and the remainder consists of organic compounds such as aldehydes, ketones and other miscellaneous compounds (9). Organic constituents in mainstream smoke have been studied extensively, however, inorganic constituents have not been studied as intensely. In most cases, few studies of cigarette smoke composition included trace metal analysis and even fewer reported mercury results. The metal concentration in cigarette smoke depends on several factors, such as the soil in which the tobacco is grown, air pollution, the variety of tobacco and the processing of tobacco leaves. Trace element analysis for mainstream cigarette smoke has emphasized particulate phase analysis (9-12), but very few studies include gasphase trace elements due to low concentrations and lack of a suitable apparatus to collect volatile metallic compounds present in the gas phase. A full list of metals in mainstream smoke has been determined by ICP-MS (12), total reflection X-ray fluorescence analysis (TXRF) (12), instrumental neutron activation analysis (INAA) $(10,12)$ and graphite furnace atomic absorption spectrometry (GFAAS) (10-12). WU et al. comprehensively studied the elemental distribution in cigarette tobacco and smoke for 


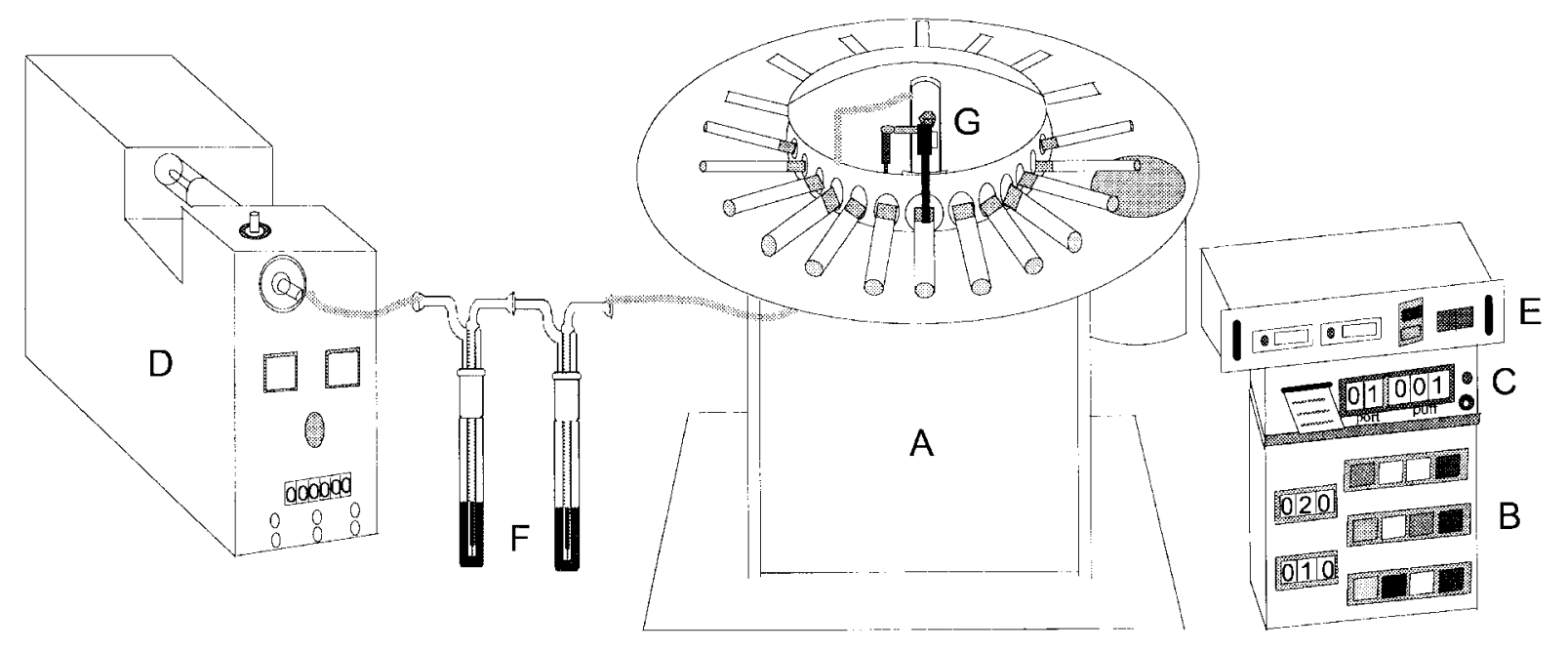

Figure 1.

Schematic of the mainstream smoke collection apparatus for mercury determination. (A) Basic unit with butt length control; (B) control panel; (C) puff counter/printer; (D) pneumatic panel; (E) power supply of electrostatic precipitation; (F) impinger trap; (G) electrostatic precipitation trap.

up to 30 elements in fifteen types of cigarettes by INAA (13). However, mercury was below the limit of detection. It has been assumed that most of the mercury exists in a gaseous state in mainstream smoke due to its high volatility, while other metals remain in the particulate phase of mainstream smoke due to their low volatility. However, no study has been found to substantiate this assumption. For those studies mentioned above, nitric acid has commonly been used in a secondary smoke collector placed directly behind the primary smoke collector to trap any gas-phase metallic compounds. However, nitric acid solution may not be efficient for the collection of gas-phase metals in mainstream smoke. A single and efficient collection system for all gaseous metallic compounds may not exist. For mercury, some techniques have been found to be fairly efficient and successful including a cooled trap $(14,15)$, solid trap $\left(\mathrm{MnO}_{2}\right)(16)$, gold amalgam $(17,18)$, and absorbing solution (19). Recently, a method for the determination of mercury in mainstream smoke has been proposed for Health Canada that utilizes potassium permanganate as an absorbing solution to collect cigarette smoke followed by analysis of mercury by CVAAS (20). The collection system utilized in the proposed Health Canada method is not capable of separating gas- and particulate-phase mercury.

Although there has been recent progress in the determination of the elemental composition of cigarette smoke, there remains a lack of information about the mercury distribution between the particulate and the gas phases. In this work, a method to separately collect and analyze gasphase and particulate-phase mercury in mainstream cigarette smoke was developed. Particulate-phase mercury is collected by electrostatic precipitation (EP) and then analyzed by gold amalgamation CVAAS. Gas-phase mercury is trapped by acidic potassium permanganate solu- tions in impinger traps and then analyzed by the CVAAS. Moreover, the effect of mainstream smoke collection parameters was also studied for the $1 \mathrm{R} 4 \mathrm{~F}$ Kentucky reference cigarette based on two smoking regimes, the Federal Trade Commission (FTC) and the alternative smoking regime currently recommended by the Massachusetts Department of Health.

\section{MATERIALS AND METHODS}

\section{Instrumentation}

The apparatus used for mainstream smoke collection is shown diagrammatically in Figure 1. A modified Borgwaldt 20-port rotary smoking machine (RM-20/CSR; H. Borgwaldt, Hamburg, Germany) was used to perform cigarette smoking. A standard electrostatic smoke trap equipped with a quartz precipitation tube (H. Borgwaldt, Hamburg, Germany) was used to collect cigarette smoke condensate. In order to reduce the risk of potential metal contamination, several modifications were made to the RM-20/CSR and the electrostatic trapping system. For the Borgwaldt 20-port rotary smoking machine, the inner portion of the sealing segment $(\mathrm{P} / \mathrm{N}$ R20.0378.01) that is exposed to the mainstream smoke was laminated with polypropylene, and the cigarette holder ( $\mathrm{P} / \mathrm{N}$ 80210220) was constructed of polypropylene. For the electrostatic precipitation system, a high purity tungsten charging electrode made from 1.6- $\mathrm{mm}$ diameter tungsten wire, and sharpened at the working end, was employed instead of the standard aluminum electrode. According to SNEDDON $(21,22)$, minimization of the diameter of the charging electrode increases the current density at the charging end which helps to achieve higher precipitation 
Table 1.

PE 5100 PC instrument operating conditions

\begin{tabular}{ll}
\hline Integration time (s) & 30 \\
Data processing & Peak height, 19 points smoothing \\
Lamp & Mercury EDL \\
Slit width & $0.7 \mathrm{~nm}$ \\
Wavelength & $253.7 \mathrm{~nm}$ \\
\hline
\end{tabular}

Table 2.

Perkin-Elmer FIAS 400 program for conventional CVAAS

\begin{tabular}{l|c|c|c|c|c}
\hline Step & $\begin{array}{c}\text { Time } \\
(\mathrm{sec})\end{array}$ & $\begin{array}{c}\text { Pump 1 } \\
\text { speed } \\
(\mathrm{rpm})\end{array}$ & $\begin{array}{c}\text { Pump 2 } \\
\text { speed } \\
\text { (rpm) }\end{array}$ & $\begin{array}{c}\text { Valve } \\
\text { Position }\end{array}$ & Read \\
\hline $\begin{array}{l}\text { Prefill } \\
15\end{array}$ & 100 & 120 & Fill & \\
1 & 10 & 100 & 120 & Fill & * \\
2 & 20 & 0 & 120 & Inject & \\
\hline
\end{tabular}

efficiency of particles from an aerosol. A dedicated highvoltage power supply unit, SL 30PN30/SL (Spellman High Voltage Electronics Corp., Hauppauge, NY, USA) set to $13 \mathrm{kV}$ was used to control the electrostatic precipitation trap and consequently generate an electric field within the electrostatic precipitation collector. The electrical connection between the electrostatic precipitation trap and power supply was made with a shielded high voltage cable $(\mathrm{P} / \mathrm{N}$ 80210162, KC Automation Inc., Richmond, VA, USA). The 250-mL impinger collection trap without frit was made of glass with 24/40 female inlet and standard insert with $12 / 5$ ball and socket, $24 / 40$ joint, and a $1.6-\mathrm{mm}$ delivery orifice (Research Glass, Richmond, VA, USA). Two impingers, each filled with $25 \mathrm{~mL}$ of acidic potassium permanganate solution, were connected in series to the EP trap for gas-phase mercury collection. The outlet of the impinger assembly was connected to a Cambridge filter on the Pneumatic Panel of the RM-20/CSR rotary smoking machine. This Cambridge filter was placed after the impingers to collect CSC breakthrough and any CSC breakthrough was monitored to assure the performance of the smoke collection apparatus.
A CEM Model MDS-2000 (CEM Corp., Matthews, NC, USA) with advanced composite vessels (ACV) was used for sample digestion. It has a carousel with 12 positions and delivers approximately $630 \mathrm{~W}$ at full power. As a general rule, $30 \%$ power is applied for one vessel, and a $5 \%$ increase in power for each additional vessel.

A Perkin-Elmer Flow Injection Analysis System, FIAS400 (Bodenseewerk Perkin-Elmer, Uberlingen, Germany), interfaced to a Perkin-Elmer Model 5100 PC spectrometer (Perkin Elmer Corp., Norwalk, CT, USA) was used in this study. The PE 5100 PC spectrometer operating conditions are shown in Table 1 . The FIAS400, equipped with an Au-Pt amalgamation system and AS 90 autosampler, has two independent peristaltic pumps, one controls sample flow and the other controls the flow of reductant, acid carrier and waste. Tables 2 and 3 detail the operating conditions of the FIAS- 400 with and without the amalgamation system, respectively. The amalgamation system attached to the FIAS- 400 was used to analyze cigarette smoke condensate (particulate phase) because it provides better sensitivity by pre-concentrating mercury vapor onto the Au-Pt gauze. A quartz absorption cell $(160 \mathrm{~mm} \times 7 \mathrm{~mm})$ with removable quartz windows in a heating mantle replaced the flame burner of the PE 5100 PC spectrometer. The quartz cell temperature was maintained at $100^{\circ} \mathrm{C}$ to avoid moisture condensation on the quartz window. Argon was used as the carrier gas at a flow rate of $75 \mathrm{~mL} / \mathrm{min}$. For conventional CVAAS, a plastic gas-liquid separator with an exchangeable PTFE membrane filter was used to separate gas and liquid because it has a small dead volume and hence provides better sensitivity than a glass separator (23). For amalgam CVAAS, a glass liquid-gas separator filled with glass beads was used because it prevents water droplets from entering the glass fiber filter in the amalgam system.

\section{Reagents}

The concentrated nitric acid was Optima grade from Fisher Scientific (Atlanta, GA, USA). The hydrogen peroxide (30\%) was ULTREX grade from J. T. Baker (Philipsburg, NJ, USA). The concentrated hydrochloric acid used for the CSC digestion for amalgamation was

Table 3.

Perkin-EImer FIAS 400 program for amalgamation CVAAS

\begin{tabular}{l|c|c|c|c|c|c|c|c}
\hline Step & $\begin{array}{c}\text { Time } \\
(\mathrm{s})\end{array}$ & $\begin{array}{c}\text { Pump 1 } \\
\text { speed } \\
\text { (rpm) }\end{array}$ & $\begin{array}{c}\text { Pump 2 } \\
\text { speed } \\
\text { (rpm) }\end{array}$ & $\begin{array}{c}\text { Valve } \\
\text { position }\end{array}$ & Read step & Heat & Cool & Argon \\
\hline Prefill & 10 & 100 & 40 & Fill & & $*$ & $*$ & $*$ \\
1 & 20 & 100 & 40 & Fill & & & $*$ \\
2 & 30 & 0 & 120 & Inject & & $*$ & $*$ \\
3 & 30 & 0 & 40 & Fill & $*$ & $*$ & $*$ \\
4 & 10 & 0 & 40 & Fill & $*$ & & $*$ \\
5 & 20 & 0 & 40 & Fill & & & $*$ \\
6 & 1 & 0 & 0 & Fill & & & $*$ \\
\hline
\end{tabular}


Optima grade from Fisher Scientific (Atlanta, GA, USA). The concentrated sulfuric acid used for the impinger solution in conventional CVAAS was Certified ACS Plus grade from Fisher Scientific (Atlanta, GA, USA). High purity double de-ionized water $(18 \mathrm{M} \Omega / \mathrm{cm})$ generated from a Milli-Q Plus Total Water System (Millipore Corp., Bedford, MA, USA) was used to prepare all solutions. Five percent $\mathrm{KMnO}_{4}$ (specific for trace mercury analysis) and concentrated $\mathrm{H}_{2} \mathrm{SO}_{4}$, both from Fisher Scientific (Atlanta, GA, USA) were used to prepare the impinger trap solution $\left(4 \% \mathrm{KMnO}_{4}\right.$ in $\left.20 \% \mathrm{H}_{2} \mathrm{SO}_{4}\right)$. The hydroxylamine hydrochloride solution (Fisher Scientific, Atlanta, GA, USA) was $10 \%$ w/v prepared in de-ionized water and was used to reduce excess $\mathrm{KMnO}_{4}$ in the digestate. The stannous chloride solution (Fisher Scientific, Atlanta, GA, USA ) was $1.1 \%$ w/v prepared in $3 \% \mathrm{HCl}$ $(v / v)$ and used as a reductant. $3 \% \mathrm{HCl}$ solution was used as the carrier. Calibration standards were prepared daily by serial dilution of a $1000 \mathrm{mg} / \mathrm{L}$ mercury stock solution (SPEX Industries Inc, Metuchen, NJ, USA). A quality control sample was prepared from a source $(1000 \mathrm{mg} / \mathrm{L}$ mercury, Perkin Elmer Corp., Norwalk, CT, USA) different from that used to prepare the calibration standards. All labware was pre-cleaned before use by soaking the labware for a minimum of $24 \mathrm{~h}$ in $20 \%$ nitric acid (aqueous). After soaking, the labware was rinsed thoroughly with reagent water, dried in a class 100 clean bench and stored in a class 100 clean room until needed.

\section{Smoke collection and sample preparation}

Cigarettes were conditioned at $22 \pm 1{ }^{\circ} \mathrm{C}$ and $60 \% \pm 2 \%$ relative humidity for a minimum of $48 \mathrm{~h}$ and smoking was conducted in a room controlled at $22 \pm 2{ }^{\circ} \mathrm{C}$ and $60 \% \pm$ $5 \%$. The number of cigarettes smoked, usually 10 to 40 cigarettes, was dependent on the CSC delivery. A sufficient amount of smoke condensate was collected in order to remove a $100 \mathrm{mg}$ portion for digestion. Two smoking regimes were employed for smoking, one is the FTC and the other is the alternative smoking regime which is specified by the Massachusetts Department of Health. The puff parameters for the FTC smoking regime are $35 \pm 0.5 \mathrm{~mL}$ puff volume with a $2 \pm 0.2 \mathrm{~s}$ puff duration once every 60 $\pm 1 \mathrm{~s}$ interval. The puffing parameters for the alternative Massachusetts smoking regime are $45 \pm 0.5 \mathrm{~mL}$ puff volume with $2 \pm 0.1 \mathrm{~s}$ puff duration once every $30 \pm 1 \mathrm{~s}$ with $50 \%$ of any cigarette ventilation holes covered. A strip of transparent adhesive tape, Scotch brand product no. 600 or equivalent, was used to block the ventilation. A predetermined number of cigarettes were smoked on the modified 20-port Borgwaldt smoking machine. Filtered cigarettes were smoked to a butt length of tipping plus $3 \mathrm{~mm}$ or $23 \mathrm{~mm}$, whichever was longer. Non-filtered cigarettes were smoked to a $23-\mathrm{mm}$ butt length. The EP trap collected the mainstream smoke particulate phase. Two impingers connected in series containing acidic potassium permanganate were placed immediately after the EP trap to collect the gas phase.
After the smoke collection was complete, the contents of the two impingers were quantitatively transferred to an advanced composite vessel (ACV) for closed vessel microwave digestion. The digestion program consisted of four stages with pressure settings of 40, 70, 100 and 150 psi, respectively. For all stages, the microwave power setting was $85 \%$ of full power, the fan speed was $100 \%$, the run time was set to $15 \mathrm{~min}$, and the time at pressure was 5 min. After digestion, the excess permanganate was reduced to Mn (II) by addition of $5 \mathrm{~mL}$ of $10 \%$ hydroxylamine hydrochloride and the digestate was brought to a final volume of $100 \mathrm{~mL}$.

For particulate-phase mercury, the amount of smoke condensate collected was measured by the difference in the weight of the EP quartz tube before and after smoking. A portion of the smoke condensate (approximately $100 \mathrm{mg}$ ) was removed from the EP tube with a polypropylene spatula and transferred to the ACV vessel followed by addition of $5 \mathrm{~mL}$ of concentrated nitric acid and $1 \mathrm{~mL}$ of $30 \%$ hydrogen peroxide for microwave digestion. A mixture of $\mathrm{HNO}_{3}$ and $\mathrm{H}_{2} \mathrm{O}_{2}$ was found to be the most effective for reliable determination of mercury for the moss and soil humus samples (24). The digestion program for the CSC was basically the same as the impinger trap solution except the program consisted of five stages with pressure settings of 20,40,85, 150 and 175 psi. After cooling to room temperature, the contents were quantitatively transferred to a $50-\mathrm{mL}$ volumetric flask, diluted to about $40 \mathrm{~mL}$ with reagent water, followed by the addition of $1 \mathrm{~mL}$ of hydrochloric acid, and adjusted to a final volume of $50 \mathrm{~mL}$. The hydrochloric acid was used to reduce the adsorption of mercury onto the wall of the sample container by forming mercuric chloride.

\section{Instrument calibration}

A calibration blank and six calibration standards up to 10 $\mu \mathrm{g} / \mathrm{L}$ were used to calibrate the instrument prior to the analysis of samples by the conventional CVAAS. For the gold amalgamation CVAAS, one calibration blank and four calibration standards up to $1 \mu \mathrm{g} / \mathrm{L}$ were used to calibrate the instrument. A $20-\mu \mathrm{L}$ aliquot of $5 \% \mathrm{KMnO}_{4}$ was added to $100 \mathrm{~mL}$ of calibration standard to preserve the mercury. Furthermore, the standards for the amalgamation system were preserved with an additional $2 \mathrm{~mL}$ of concentrated hydrochloric acid. All calibration standards were freshly prepared daily prior to instrument calibration because the concentration of mercury can change with aging. A quality control sample in the middle range of the calibration curve was also prepared daily and analyzed immediately after calibration. Successful analysis of the quality control sample verified the accuracy of the calibration curve and the analytical system. The limit of detection (LOD) was determined by three times the standard deviation of the reagent blank analyzed in 10 replicates. The LOD is $0.05 \mu \mathrm{g} / \mathrm{L}$ for the conventional CVAAS with a $500-\mu \mathrm{L}$ sample loop and is $0.015 \mu \mathrm{g} / \mathrm{L}$ for the gold amalgamation CVAAS with ten $500-\mu \mathrm{L}$ injections. 


\section{RESULTS AND DISCUSSION}

\section{Collection efficiency}

The collection efficiency of cigarette smoke for mercury determination can be classified into two components according to characteristics of the collection apparatus, electrostatic precipitation for the particulate phase and impinger traps for the gas phase. For the particulate phase, the collection efficiency of electrostatic precipitation depends on many variables such as operating parameters (voltage, current and flow rate) and particle parameters (particle size, shape, dielectric properties and mass loading). The electrode used in this study was ground to a sharp point on an industrial grinder to increase the collection efficiency. The Cambridge pad attached to the pneumatic panel of the Borgwaldt 20-port rotary smoking machine was used to collect any CSC breakthrough after the impinger trap. It was weighed before and after smoking and compared to the CSC collected on the electrostatic precipitation quartz tube to calculate the trap efficiency of the smoke collection system. In general, the CSC breakthrough was about $1 \%$ or less and the overall collection efficiencies were high enough to separate the particulate phase from the gas phase satisfactorily. For the gas phase, the individual collection efficiency of the impinger solution was also investigated before establishing the number of impingers needed for mainstream smoke collection. In the beginning, two impingers were connected in series, and each was independently treated and analyzed as an individual sample. In this experiment, the mercury concentration in the first impinger was about $92 \%$ of the total measured mercury and the second impinger collected about $8 \%$ of the total mercury. Assuming that each impinger is able to collect $90 \%$ of the mercury passing through, two impingers should be able to collect about $99 \%$ of the total mercury, and the breakthrough should be trivial for two impingers connected in series. To determine the optimum trap concentration for gasphase mercury, 40 cigarettes were smoked during two smoking runs, and whole mainstream smoke was transported to a trap solution that contained a variety of acidic potassium permanganate concentrations. The efficiency of a trap solution comprised of $1 \%$ potassium permanganate in $20 \%$ sulfuric acid apparently was not sufficient, as indicated by a color change of the impinger solution from purple to black during the smoking process. The reason for the color change was that reactions between whole smoke and permanganate consumed all of the permanganate. In order to alleviate the load of smoke condensate going to the impinger solution, electrostatic precipitation was applied to remove the particulate phase and the acidic potassium permanganate solution was used to collect the gas-phase mercury. By comparing the mercury content in the mainstream smoke of a $1 \mathrm{R} 4 \mathrm{~F}$ reference cigarette, the trap efficiency of the impinger solution was investigated and compared by using various concentration combinations of sulfuric acid, potassium persulphate, and potas- sium permanganate. The potassium persulphate was used for this test because it can oxidize organic mercury better than potassium permanganate. Without electrostatic precipitation, a trap solution containing $1 \%$ potassium persulphate and $1 \%$ potassium permanganate in $20 \%$ sulfuric acid resulted in an $80 \%$ trap efficiency compared to a trap solution of $4 \%$ potassium permanganate in $20 \%$ sulfuric acid. However, the trap efficiency for both trap solutions agreed quite well with each other, if electrostatic precipitation was applied to remove the particulate phase. The electrostatic precipitation trap collects most of the particulate phase and hence reduces the burden on the impinger trap solution. To ensure trapping of all mercury released in cigarette smoke for a variety of cigarettes, a $4 \%$ potassium permanganate in $20 \%$ sulfuric acid mixture was chosen as the impinger solution and electrostatic precipitation was used as the particulate phase trap.

\section{Mercury distribution between particulate phase and gas phase}

In the above mentioned collection efficiency study for the $1 \mathrm{R} 4 \mathrm{~F}$ reference cigarette, the mercury concentration in the potassium permanganate impinger traps with and without electrostatic precipitation was not statistically different. The total mercury (including both gas phase and particulate phase) for the $1 \mathrm{R} 4 \mathrm{~F}$ reference cigarette without electrostatic precipitation was $4.8 \pm 0.1 \mathrm{ng} / \mathrm{cig}$ based on five replicates, compared to $4.9 \pm 0.3 \mathrm{ng} / \mathrm{cig}$ for gas-phase mercury using electrostatic precipitation. This suggests that the mercury level in the particulate phase is very low and probably insignificant. These results and the lack of reported literature values for particulate phase mercury indicate that the distribution of mercury between the gas and particulate phases in cigarette smoke needs to be further investigated. As shown in Table 4, the mercury concentration in the particulate phase was less than $0.2 \mathrm{ng} / \mathrm{cig}$ for the $1 \mathrm{R} 4 \mathrm{~F}$ cigarette smoked under the two smoking regimes. It was reported that mercury in the particulate phase is below the quantitation limit for the C-20 and the Marlboro cigarettes $(10,12)$. Our results agree with this finding. Furthermore, these results indicate that the majority of mercury exists in the gas phase after volatilization of elemental $\mathrm{Hg}$ and thermal decomposition of mercuric compounds during cigarette combustion. The mercury concentration in the particulate phase is negligible.

The US Environmental Protection Agency (EPA) has recently adopted a direct mercury analytical method based on thermal decomposition, SW-846 method 7473 (25). The primary advantage of this method is that tedious sample preparation for conventional mercury analysis has been eliminated. A temperature of $750^{\circ} \mathrm{C}$ is applied for the pyrolysis of a variety of sample matrices such as soils, sediments, sludge, aqueous wastes and ground water. After pyrolysis, the gas-phase mercury is trapped selectively by the gold amalgamator, released by thermal desorption and analyzed by atomic absorption 
Table 4.

Comparison of mercury in gas phase and particulate phase for mainstream smoke under FTC and alternative smoking conditions for $1 \mathrm{R} 4 \mathrm{~F}$ reference cigarette

\begin{tabular}{|c|c|c|c|c|}
\hline Parameters investigated & \multicolumn{2}{|c|}{ 1R4F } & $\operatorname{LOD}^{a}$ & Published data \\
\hline Smoking regime & $\begin{array}{c}\text { FTC } \\
(\text { Mean } \pm \text { stdev) }\end{array}$ & $\begin{array}{c}\text { Alternative } \\
\text { (Mean } \pm \text { stdev) }\end{array}$ & & \\
\hline Hg in gas phase (ng/cig) & $\begin{array}{c}4.9 \pm 0.3 \\
(n=5)\end{array}$ & $\begin{array}{c}8.0 \pm 0.4 \\
(n=20)\end{array}$ & 0.3 & $7.73 \pm 1.82^{b}$ \\
\hline $\mathrm{Hg}$ in particulate phase $(\mathrm{ng} / \mathrm{cig})$ & $\begin{array}{l}<0.2 \\
(n=3)\end{array}$ & $\begin{array}{l}<0.2 \\
(n=3)\end{array}$ & 0.2 & $\begin{array}{l}4^{\mathrm{c}} \\
<1.0^{\mathrm{d}} \\
<0.5^{\mathrm{e}}\end{array}$ \\
\hline CSC delivery (mg/cig) & $\begin{array}{c}10.3 \pm 0.6 \\
(n=6)\end{array}$ & $\begin{array}{c}26.9 \pm 2.1 \\
(n=20)\end{array}$ & & $\begin{array}{l}10.8^{f} \\
9.3^{f}\end{array}$ \\
\hline Puff count & $\begin{array}{c}9.0 \pm 0.1 \\
(n=5)\end{array}$ & $\begin{array}{c}13.7 \pm 0.3 \\
(n=20)\end{array}$ & & $\begin{array}{l}9.2^{f} \\
8.5^{f}\end{array}$ \\
\hline Number of cigarettes smoked & 40 & 20 & & \\
\hline
\end{tabular}

${ }^{\mathrm{a}} \mathrm{LOD}=$ limit of detection.

${ }^{\mathrm{b}} 1 \mathrm{R} 4 \mathrm{~F}$ cigarette with a background contamination of $0.78 \mathrm{ng} / \mathrm{cig}(20)$.

c1R1 cigarette (9).

${ }^{\mathrm{d}} \mathrm{C}-20$ cigarette $(10,12)$.

eMarlboro cigarette $(10,12)$.

${ }^{\mathrm{f}} 1 \mathrm{R} 4 \mathrm{~F}$ cigarette (11).

spectrometry. Cigarette smoking is a pyrolysis process similar to the thermal decomposition for direct mercury analysis. The boiling point of the mercury, $356.7^{\circ} \mathrm{C}$, is quite low compared to other metals and the temperature in the combustion zone of the cigarette can reach approximately $700-900{ }^{\circ} \mathrm{C}$, which is high enough to vaporize $\mathrm{Hg}$ and thermally decompose and/or carbothermally reduce mercury compounds. Mercuric oxide for example, can easily decompose into mercury and oxygen at a temperature of $500^{\circ} \mathrm{C}$. After thermal sublimation, there might be a chance for the gaseous mercury to be adsorbed and then condensed back to the cigarette filler. If mercury can be bound to the unburned tobacco, paper, ash, butt or filter, it could be regenerated during consecutive puffs.

\section{Effect of changing the cigarette smoking parameters}

It is well known that the cigarette smoke delivery is dependent on the smoking conditions, i.e., puff volume, puff count, ventilation, puff duration and interval. Altering the smoking regime has an influence on both mainstream and sidestream cigarette smoke delivery. To investigate the effect of smoking regime on the mercury yield in the gas phase, cigarettes were smoked under the FTC and the alternative Massachusetts smoking parameters. In addition to the delivery of cigarette smoke condensate and the puff count, the mercury concentrations for $1 \mathrm{R} 4 \mathrm{~F}$ reference cigarette were compared in Table 4 under two smoking regimes as well as with published data. The alternative smoking regime, $50 \%$ ventilation holes blocked, larger puff volume, and shorter puff interval, represents a more intense smoking process than the FTC smoking regime, and thus results in a higher CSC delivery for mainstream smoke. For 1R4F, the amount of CSC for the alternative smoking regime is approximately twice that for the FTC smoking regime, $26.9 \pm 2.1$ $\mathrm{mg} / \mathrm{cig}$ vs. $10.3 \pm 0.6 \mathrm{mg} / \mathrm{cig}$. The gas-phase mercury content in mainstream smoke is $8.0 \pm 0.4 \mathrm{ng} / \mathrm{cig}$ for the alternative smoking regime compared to $4.9 \pm 0.3 \mathrm{ng} / \mathrm{cig}$ for the FTC smoking regime. Most of the published data exclusively refer to the particulate-phase mercury in cigarette smoke because of the lack of a suitable method for collecting gas-phase mercury. The proposed method of Health Canada reports a total mercury concentration of $7.73 \pm 1.82 \mathrm{ng} / \mathrm{cig}$ for the $1 \mathrm{R} 4 \mathrm{~F}$ reference cigarette, which includes both particulate-phase and gas-phase mercury under the FTC smoking parameters. However, there is no information concerning the mercury distribution between the particulate and the gas phase. There is about $3 \mathrm{ng} /$ cig difference in mainstream mercury found for the 1R4F cigarette smoking under the FTC smoking regime between the proposed method of Health Canada and our current method. This difference could be attributed to the purity of reagents used to prepare the impinger trap solution (especially potassium permanganate), and the laboratory environmental air quality. There is an average observed level of background contamination of $0.78 \mathrm{ng} / \mathrm{cig}$ of mercury in the proposed method for Health Canada.

For the same type of cigarette, a larger puff volume and higher puff count per cigarette deliver more cigarette smoke (particulate and gas phase) to the mainstream and hence decompose and release more mercury to mainstream smoke, as shown in Table 4. This comparison of 
Table 5.

Kentucky reference cigarette (1R4F) spike recovery results

\begin{tabular}{l|c|c|c}
\hline & $\begin{array}{c}\text { No. of cig. } \\
\text { smoked }\end{array}$ & $\begin{array}{c}\text { Spike level } \\
\text { (ng) }\end{array}$ & $\begin{array}{c}\text { Recovery (\%) } \\
\text { (Mean } \pm \text { stdev) }\end{array}$ \\
\hline $\mathrm{Hg}$ in gas phase & 40 & 200 & $98 \pm 8(\mathrm{n}=3)$ \\
$\mathrm{Hg}$ in particulate \\
phase
\end{tabular}

mercury delivery under different smoking regimes suggests that mercury could redistribute between mainstream and sidestream smoke by changing the cigarette smoking parameters. Any increase of mercury in the mainstream smoke probably comes as a result of decrease sidestream smoke mercury.

\section{Selectivity and accuracy}

Any gaseous compounds that absorb at the wavelength of mercury such as chlorine, nitrogen dioxide and volatile organic material may result in a false positive number, if they are swept into the analytical cell with mercury vapor in the atomic absorption spectrometer. Therefore, to confirm our mercury results, conventional CVAAS as well as amalgamation CVAAS were used to analyze the same impinger solutions containing gas-phase mercury of cigarette smoke. The injection volume was kept at $500 \mu \mathrm{L}$ for both conventional CVAAS and amalgamation CVAAS, although the amalgamation technique can use more sample volume with multiple injections. The mercury concentration analyzed by amalgamation CVAAS was $96 \%$ of that analyzed by conventional CVAAS, which is within the variation of the analytical method. The analytical precision for gas-phase mercury determination is about $6 \%$ relative standard deviation (RSD) from Table 4. Therefore, the microwave-digested sample is free of interference and is suitable for the determination of gas-phase mercury by CVAAS.

In order to assess the accuracy, spike recoveries were performed on both particulate-phase in four replicates and gas-phase mercury in three replicates, and the results are shown in Table 5. For gas-phase mercury, $200 \mathrm{ng}$ of mercury was spiked into the first impinger solution before smoking 40 cigarettes under FTC smoking parame- ters. After smoking, the spiked samples were treated and analyzed exactly like a smoke sample. The spike recovery was $98 \% \pm 8 \%$ for gas-phase mercury. This indicates no matrix interference and no mercury lost during the smoking process and sample preparation. For particulate-phase mercury, a separate portion of smoke condensate (about $100 \mathrm{mg}$ ) was removed from the EP tube after smoking and $25 \mathrm{ng}$ of mercury was spiked into it before microwave digestion. The spike recovery for the smoke condensate was $97 \% \pm 2 \%$ which indicates no mercury was lost during microwave digestion of cigarette smoke condensate.

\section{Mercury in high and low CSC delivery cigarettes}

The relationship between CSC delivery and mercury content was further investigated by analyzing two different Philip Morris USA cigarette market brands in addition to the 1R4F reference cigarette. The Basic King Nonfilter SP is a high CSC delivery cigarette and conversely the Merit 100 Filter SP Ultima is a low CSC delivery cigarette. These two cigarettes were smoked according to the alternative Massachusetts smoking regime in 5 replicates and then the collected gas-phase mercury was analyzed by conventional CVAAS. The average of mercury contents with standard deviation is reported in Table 6 along with the $1 \mathrm{R} 4 \mathrm{~F}$ results from Table 4 . The alternative smoking parameters were used to compare the cigarette brands because larger amounts of CSC are delivered per cigarette and hence fewer cigarettes were needed for smoking. Of the two brands, the Basic King Non-filter SP cigarette has the highest CSC delivery $(60.4 \pm 1.4 \mathrm{mg} / \mathrm{cig})$ with a mercury concentration of $5.7 \pm 0.1 \mathrm{ng} / \mathrm{cig}$, while the Merit 100 F SP Ultima cigarette has the lowest CSC delivery $(10.7 \pm 1.0 \mathrm{mg} / \mathrm{cig})$ with a mercury concentration of $3.6 \pm 0.2 \mathrm{ng} / \mathrm{cig}$. However, the $1 \mathrm{R} 4 \mathrm{~F}$ reference cigarette has the highest mercury concentration of $8.0 \pm$ $0.4 \mathrm{ng} / \mathrm{cig}$, but with a medium CSC delivery, $26.9 \pm 2.1$ $\mathrm{mg} / \mathrm{cig}$. The $50 \%$ ventilation holes blocked regime was not applied to the Basic King Non-filter SP cigarette because it has no ventilation holes. For the cigarettes in this work, the mercury concentration in the mainstream smoke is not proportional to the CSC delivery unless the same types of cigarettes are smoked as shown in Table 4. The physical variables in the cigarette (mass, cigarette filter and paper, and ventilation) may also play an impor-

Table 6.

Comparison of the mercury concentration in mainstream smoke for 1R4F reference cigarette, Basic King NF SP cigarette, and Merit $100 \mathrm{~F} \mathrm{SP}$ cigarette smoked under alternative smoking parameters

\begin{tabular}{l|c|c|c}
\hline Parameters investigated & $\begin{array}{c}1 \mathrm{R} 4 \mathrm{~F} \\
(\mathrm{n}=20) \\
(\text { Mean } \pm \mathrm{stdev})\end{array}$ & $\begin{array}{c}\text { Basic King NF SP } \\
(\mathrm{n}=5) \\
(\text { Mean } \pm \text { stdev })\end{array}$ & $\begin{array}{c}\text { Merit 100 F SP } \\
(\mathrm{n}=5) \\
(\text { Mean } \pm \text { stdev })\end{array}$ \\
\hline Hg in gas phase (ng/cig) & $8.0 \pm 0.4$ & $5.7 \pm 0.1$ & $3.6 \pm 0.2$ \\
CSC delivery (mg/cig) & $26.9 \pm 2.1$ & $60.4 \pm 1.4$ & $10.7 \pm 1.0$ \\
Puff count & $13.7 \pm 0.3$ & $13.6 \pm 0.2$ & $10.5 \pm 0.3$ \\
Number of cigarettes smoked & 20 & 10 & 20 \\
\hline
\end{tabular}


tant role in the mercury delivery for the mainstream smoke in addition to the tobacco. The soil and atmospheric conditions under which the tobacco was grown may affect the mercury content in the tobacco used to prepare the cigarettes. The $1 \mathrm{R} 4 \mathrm{~F}$ cigarette was fabricated by the University of Kentucky in 1983 and its tobacco was grown earlier than the tobacco for Basic King Nonfilter SP and Merit 100 F SP Ultima cigarettes.

\section{CONCLUSIONS}

The determination of gas-phase and particulate-phase mercury in mainstream smoke was performed by cold vapor atomic absorption spectrometry with and without the amalgamation technique. Electrostatic precipitation was used to separate the particulate from the gas phase of cigarette smoke. Gas-phase mercury was successfully collected with two impingers in series containing acidic potassium permanganate. Our work demonstrates that the majority of mercury is present in the gas phase of mainstream smoke and a negligible amount exists in the particulate phase. For simplicity in practical analytical work, it should be adequate to determine the mercury concentration in mainstream cigarette smoke by analyzing only gas-phase mercury. The mercury level in the $1 \mathrm{R} 4 \mathrm{~F}$ reference cigarettes increases with increasing cigarette smoke condensate (CSC) delivery. Based on the data obtained for the different cigarette brands evaluated in this study, mainstream CSC delivery cannot be used to predict the mainstream gas-phase mercury delivery.

\section{Acknowledgements}

The authors would like to thank Dr. Ken F. Podraza, director of the Analytical Method and Application Division of Research, Development and Engineering as well as the management of Philip Morris USA for their support in this work.

\section{REFERENCES}

1. Zhang, D.-Q., Z.-M. Ni, and H.-W. Sun: Stabilization of organic and inorganic mercury in the graphite furnace with $\left(\mathrm{NH}_{4}\right)_{2} \mathrm{PdCl}_{6}-\left(\mathrm{NH}_{4}\right)_{3} \mathrm{RhCl}_{6}$ as a mixed chemical modifier; Spectrochim. Acta 53B (1998) 1049-1055.

2. Rudner, P.C., A. Garcia de Torres, J.M.C. Pavon, and E.R.Castellon: Automated on-line separationpreconcentration system for inductively coupled plasma atomic emission spectrometry and its application to mercury determination; J. Anal. At. Spectrom. 13 (1998) 243-248.

3. Powell, M.J., E.S.K. Quan, D.W. Boomer, and D.R. Wiederin: Inductively coupled plasma mass spectrometry with direct injection nebulization for mercury analysis of drinking water; Anal. Chem. 64 (1992) 2253-2257.
4. Allibone, J., E. Fatemian, and P.J. Walker: Determination of mercury in portable water by ICP-MS using gold as a stabilising agent; J. Anal. At. Spectrom. 14 (1999) 235-239.

5. Woller, A., H. Garraud, F. Martin, O.F.X. Donard, and P. Fodor: Determination of total mercury in sediments by microwave-assisted digestion-flow injection-inductively coupled plasma mass spectrometry; J. Anal. At. Spectrom. 12 (1997) 53-56.

6. Debrah, E., E.R. Denoyer, and J.F. Tyson: Flow injection determination of mercury with preconcentration by amalgamation on a gold-platinum gauze by inductively coupled plasma mass spectrometry; J. Anal. At. Spectrom. 11 (1996) 127-132.

7. Bloxham, M.J., S.J. Hill, and P.J. Worsfold: Determination of mercury in filtered sea-water by flow injection with on-line oxidation and atomic fluorescence spectrometric detection; J. Anal. At. Spectrom. 11 (1996) 511-514.

8. Gamiz-Gracia, L. and M.D. Luque de Castro: Determination of mercury in cosmetics by flow injectioncold vapour generation-atomic fluorescence spectrometry with on-line preconcentration; J. Anal. At. Spectrom. 14 (1999) 1615-1617.

9. Norman, V.: An overview of the vapor phase, semivolatile and nonvolatile components of cigarette smoke; Rec. Adv. Tob. Sci. 3 (1977) 28-58.

10. Schneider, G. and V. Krivan: Multi-element analysis of tobacco and smoke condensate by instrumental neutron activation analysis and atomic absorption spectrometry; Intern. J. Environ. Anal. Chem. 53 (1993) 87-100.

11. Rhoades, C.B. and R.T. White : Mainstream smoke collection by electrostatic precipitation for acid dissolution in a microwave digestion system prior to trace element determination; J. Assoc. Off. Anal. Chem. 80 (1997) 1320-1331.

12. Krivan, V., G. Schneider, H. Baumann, and U. Reus: Multi-element characterization of tobacco smoke condensate; Fresenius J. Anal. Chem. 348 (1994) 218-225.

13. Wu, D., S. Landsberger, and S.M. Larson: Determination of the elemental distribution in cigarette components and smoke by instrumental neutron activation analysis; J. Radioanal. Nucl. Chem. 217 (1997) 77-82.

14. Aston, S.R. and J.P. Riley: The determination of mercury in rocks and sediments; Anal. Chim. Acta 59 (1972) 349-354.

15. Cavalli, P. and G. Rossi: Determination of submicrogram amounts of mercury in various matrices by flameless atomic fluorescence spectrometry; Analyst 101 (1976) 272-277.

16. Janssen, J.H., J.E. Van Den Enk, R. Bult, and D.C. De Groot: Determination of total mercury in air by atomic absorption spectrometry after collection on manganese dioxide; Anal. Chim. Acta 92 (1977) 71-77. 
17. Kozuchowski, J.: Determination of total mercury in sediments by furnace combustion and plasma emission spectrometry; Anal. Chim. Acta 99 (1978) 293-297.

18. Dumarey, R., R. Heindryckx, and R. Dams: Determination of mercury in environmental standard reference materials by pyrolysis; Anal. Chim. Acta 118 (1980) 381-383.

19. Ebdon, L., J.R. Wilkinson, and K.W. Jackson: Determination of mercury in coal by non-oxidative pyrolysis and cold vapour atomic-fluorescence spectrometry; Analyst 107 (1982) 269-275.

20. MS-14: Determination of mercury in mainstream tobacco smoke; in: Proposed analytical methods prepared for Health Canada under contract no. H4097-7-008; Labstat Inc., Kitchener, ON, Canada, 1998.

21. Sneddon, J.: Electrostatic precipitation atomic absorption spectrometry; Appl. Spectrosc. 44 (1990) 1562-1565.

22. Sneddon, J.: Direct and near-real-time determination of lead, manganese and mercury in laboratory air by electrostatic precipitation-atomic absorption spectrometry; Anal. Chim. Acta 245 (1991) 203-206.
23. Brindle, I.D. and S. Zheng: A comparison of gasliquid separators for the determination of mercury by cold-vapour sequential injection atomic absorption spectrometry; Spectrochim. Acta 51B (1996) 1777-1780.

24. Lippo, H., T. Jauhiainen, and P. Peramaki: Comparison of digestion methods for the determination of total mercury in environmental samples by flow injection CV-AAS; At. Spectrosc. 18 (1997) 102-108.

25. U.S. E.P.A.: Test methods for the analysis of solid wastes (SW-846 Method No. 7473); Environmental Protection Agency Office of Solid Waste (OSW), Washington, DC, 1998.

Address for correspondence:

Michael J. Chang Philip Morris U.S.A. Research Development and Engineering Center 4201 Commerce Road

Richmond, VA 23234, U.S.A. e-mail: michael.chang@pmusa.com fax: (804) 274-2077 